\title{
506
}

$a b$

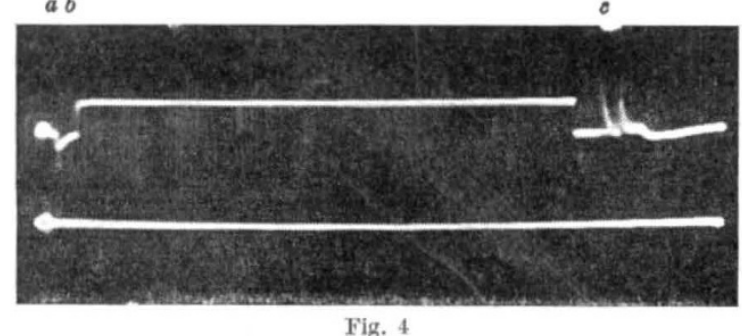

field; this trace is needed when the gun is used as a target by switching off the radio-frequency at the peak field and allowing the electron orbits to expand. On the trace shown may be seen the zero field pulse, $a$, the envelope of the rectified radio-frequency accelerating voltage, $b$, and the response, $c$, from a Geiger-Müller counter placed in the $\gamma$-ray beam. The response appears as a double pulse, a phenomenon which has been already investigated on the American 70-MeV. synchrotron, which has sufficient intensity to actuate a photomultiplier tube ${ }^{2}$.

The experimental results so far obtained with the synchrotron are qualitatively in agreement with previous results reported ${ }^{1,2}$. This first $30-\mathrm{MeV}$. machine will continue to be used to develop synchrotron techniques and to guide the design of the $140-\mathrm{MeV}$. and $300-\mathrm{MeV}$. synchrotrons which are being constructed. One of the later $30-\mathrm{MeV}$. machines, now in the stage of final commissioning, will be used as a nuclear physics tool by the Physics Department of the University of Glasgow. Two further machines are being built for the Medical Research Council for medical investigations. In addition, a machine has been modified to test whether a frequency-modulated synchrotron is practicable.

Acknowledgment is made of the assistance given to this project by our colleagues at the Telecommunications Research Establishment and by industrial firms and potential users of the machines. It is hoped. to make full acknowledgment of these contributions in later descriptions of more specialized features of the apparatus. The work described here was carried out by the Electronics Group of the Atomic Energy Research Establishment, at the Telecommunications Research Establishment, Malvern, and acknowledgment is made to Sir John Cockcroft for permission to publish the results.

${ }^{1}$ Goward and Barnes; Nature, 158, 413 (1946).

"Elder, Gurewitsch, Langmuir and Pollock, "A $70 \mathrm{MeV}$. Synchrotron", J. Appl. Phys., 18, 810 (1947).

'Kerst, Rev. Sei. Instr., 13, 387 (1942).

\section{BIOLOGY IN COLONIAL UNIVERSITIES}

$\mathrm{P}$ LANS which are in train or which have already been carried out for the setting up of university colleges in the West Indies, at Singapore, at Ibadan, Nigeria, and in the Gold Coast, as well as for the extension of Makerere College, Uganda, give point to the parallel disoussions which have been going on with regard to the content and outlook of the curriculum which should be offered in these centres of higher education for Colonial people. It has been generally agreed that subjects contributing directly to human welfare should receive greater attention than has been the case in the more ancient seats of learning in Britain; it has also been generally agreed that the subjects offered should form
April 3, 1948 Vol. 161

part of some concerted scheme. With such ends in view Dr. E. B. Edney makes out a case for the setting up in Colonial universities of single departments of biology instead of separate ones for botany and zoology ${ }^{1}$.

Dr. Edney has had experience of Colonial education as tutor in biology at Makerere College. In his article he directs attention to the fact that many problems coming under botany and zoology are really biological ; the biological approach to them is more vital and organic. For students working to 'pass' standards-and these for some time to come will be the great majority at Colonial universities-botany and zoology as taught at present, he maintains, are too morphological. One reason for this is that all human physiology is taken over by the medical schools.

So far as Colonial universities are concerned, the question may be debated in relation to three main functions : the training of teachers, applied scientists, and research workers. As regards the first it is suggested that at the school stage the aim should be to develop a biological approach built around the concept of the organism in relation to its environment. As for applied scientists, whether agriculturists, entomologists or medical practitioners, problems in the field are always biological. Training, therefore, should include instruction in biological relationships. Under present conditions such training is given only as part of vocational work.

In relation to research, Dr. Edney maintains that, in any event, a biological approach could not have a stifling effect, and that the association of workers interested in both plant and animal biology should prove a fruitful one. Fields of research like genetics, cytology and ecology are not either purely botanical or zoological, yet they are as important and attractive as any others. It might be objected that the biological approach is too general and superficial, and that concentration on the morphological and system. atic aspects of the subject is necessary for developing accuracy and an appreciation of scientific discipline. The author admits that the subject of biology is far too wide to be covered adequately in a course of two or three years, but he sees no reason why accurate and painstaking work should not be done in fields which are essentially biological, while at the same time giving due weight to considerations which are chiefly morphological.

If it is agreed that the biological approach is of value, the question remains whether the subject should be presented by two separate departments or one. For a number of reasons Dr. Edney holds that the latter would be preferable. Existing departments of zoology and botany have their own distinctive flavours; while as regards examinations, if for the new Colonial universities they are to continue to be directed from London, a single department of biology would find it easier to devise and gain acceptance for its own syllabus. Where new universities are being founded, the setting up of a department of biology would be comparatively easy ; where separate departments for botany and zoology already are in being, it might be advisable to allow them to continue, while working progressively towards closer union.

A point not touched on by Dr. Edney is the question of staffing. The supply of men of science with a genuine biological point of view is small and it is not likely rapidly to increase. To present at university standard a syllabus of the type envisaged would require the close co-operation of several men of 
science. While that would be highly desirable in itself it would not be easy to achieve. At the same time, a demand for biologists, as distinct from botanists and zoologists, would have repercussions on the universities in Britain which in the long run would be likely to be salutary.

As an appendix to his article, Dr. Edney has drawn up a three-year curriculum in biology to pass-degree standard, which may be obtained on application.

${ }^{1}$ Biology and Human Affairs, 13, 111 (1948). (British Social Hygiene Council (Inc.), Tavistock House North, London, W.C.1.)

\section{EDUCATION IN MYCOLOGY}

$\mathrm{T}$ E first duty of Prof. A. E. Muskett as president of the British Mycological Society for the ensuing year was to preside at the discussions of the Society on "Mycological Education" at its meeting on January 31. In the first paper of the session, "The Society and Mycological Education", Dr. G. C. Ainsworth reminded us that mycological education is implicit in many of the activities of the Society, not the least of these being the annual foray where amateur and professional mycologists forgather for a week of intensive study of fungi collected on daily excursions. This club meeting has done much to keep alive the "tradition of species". By its report on "The Need for Encouraging the Study of Systematic Mycology in England and Wales" printed, but not published, in 1944, and by its subsequent report on "The Teaching of Mycology" printed in 1946, but again not published, the Society focused attention on the dearth of trained mycologists and of systematists in particular, and on the need for detailed consideration of, and early action to secure, the adequate training of mycologists in the diverse fields in which present-day conditions require their services. The discussion afforded the exchange of views on the question of mycological education between mycologists of widely different interests.

Admitting that the topic of education for a specific career is always a difficult subject to review, Dr. W. G. Keyworth, in presenting the case of "Mycology for the Plant Pathologist", outlined the present course of training of a plant pathologist during the study for his initial degree. Here mycology is treated in the same way as other aspects of botany, emphasis being placed on those families showing features of taxonomic interest. Research on a specific and often rather limited field of investigation usually followed before the plant pathologist embarked on his career as an adviser or as a research worker. Valuable as the present system is, Dr. Keyworth considers that continued study of general mycology after taking a first degree is of paramount importance. This study should not only include pathogenic but also saprophytic fungi, should involve a consideration of the Fungi Imperfecti, should deal with the study of the fungi in vivo and in vitro, and should include an adequate treatment of the taxonomy of fungi. Thereafter, and before commencing professional duties, the plant pathologist destined to become an adviser might gain experience in field recognition of diseases at an advisory centre, and the plant pathologist following research work as a career might gain experience in research methods and technique as applied to pathogenic fungi. Dr. Keyworth concluded by suggesting that postgraduate courses should be instituted, and that these might well lead to a diploma or to a higher degree which could be the accepted hallmark of a sound preliminary training.

The absence of courses which completely cover the requirements of industrial microbiologists was emphasized by Dr. F. D. Armitage during his paper on "Mycology and the Industrial Microbiologist". Certain microfungi are studied as examples of moulds in courses of bacteriology, but to obtain a working knowledge of systematic mycology the microbiologist must depend on private reading of current literature -a task almost impossible without some expert guidance. He suggested that the Society might use its influence to create a school of mycology which would develop a course suitable for mycologists in industry, paying particular attention to mycologica technique, to the maintenance of culture collections, to the sampling methods applied to mycological analysis, to the study of inhibitors and to the principles of taxonomy. Failing this, the Society might organise, and later publish, a series of lectures designed for those commencing the study of microfungi. He was certain sound mycological education is a vital problem at the present time.

During his paper on "Mycology for the Medical Practitioner", Dr. I. Martin Scott suggested that the practitioner's lack of intimate knowledge of this branch of science was due to the overloaded curri. culum of the present degree and to the lack of facilities for graduate studies. Normally only a single lecture is devoted to pathogenic fungi during undergraduate courses, and in public health studies only a short course on medical my cology is available. The remedies are obvious: future undergraduates should receive systematic instruction in mycology, as they do now in bacteriology, and graduate schools for further study and for research should be estab. lished. Close collaboration between medical practitioners and mycologists is essential in this field.

The case for "Mycology for the Amateur" was ably presented by Mr. J. M. B. King, who stated that the Society offers the best place for the amateur, who takes his mycology seriously, to obtain that advice and guidance which the personal experience of its members, obtained by the study of fungi in the field, can give. The Society could further aid the amateur by sponsoring books written in as nontechnical a language as possible containing adequate keys, colour charts and fully documented glossaries of necessary technical terms. $\mathrm{He}$ believed that periodic publication in its Transactions of articles dealing with the fundamental features of fungal structure, with the principles of classification and with taxonomic problems would be appreciated. Efforts might be made to increase the number of forays and of meetings of general interest, some of which might be demonstrations of named specimens similar to that recently held.

Dealing with "Mycology and the Universities", Prof. C. G. C. Chesters stated that the orthodox training in mycology was obtained within the scope of an honours degree in botany, the fungi being treated as a section of the Thallophyta. He believed that the fungi should be removed from this phylum and might be treated as a separate discipline within the confines of botany. Since mycology must be based on a knowledge of the living fungus, collection of material in the field must play a large part in any well-balanced course, which must also include the study of the physiology, the genetics and the technique of cultivation of fungi in vitro. Graduate 